\title{
PREGNANT WOMEN'S PERCEPTION OF THE EFFECTIVENESS, SAFETY AND TIMELINESS OF ANTENATAL SERVICES PROVIDED BY MIDWIVES IN GOVERNMENT-OWNED HEALTHCARE FACILITIES IN SOUTH-SOUTH NIGERIA
}

\section{Kanikwu Phoebe Nwamaka ${ }^{1}$, Chiejina Edith Nkechi2 ${ }^{*}$ and Odira Chika C.H. ${ }^{3}$}

${ }^{1}$ Department of Nursing Science, Faculty of Applied Health Sciences, Edo State University, Uzairue, Edo State, Nigeria. Email: nwakanikwu@gmail.com

${ }^{2}$ Department of Nursing Science, Faculty of Health Sciences and Technology, Nnamdi Azikiwe

University, Awka (Nnewi Campus), Anambra State, Nigeria.

Email: nkechichiejina@yahoo.com

${ }^{3}$ Department of Nursing Science, Faculty of Health Sciences and Technology, Nnamdi Azikiwe University, Awka (Nnewi Campus), Anambra State, Nigeria.

Email: chikachioma@gmail.com

*Corresponding Authors: nkechichiejina@yahoo.com; Phone no. +2348037463279

Cite this article:

Kanikwu P.N., Chiejina E.N., Odira C.C.H. (2021), Pregnant Women's Perception of the Effectiveness, Safety and Timeliness of Antenatal Services Provided by Midwives in GovernmentOwned Healthcare Facilities in South-South Nigeria. African Journal of Health, Nursing and Midwifery 4(6), 14-28. DOI: 10.52589/AJHNMM6VY4AJR.

\section{Manuscript History}

Received: 2 Sept 2021

Accepted: 22 Sept 2021

Published: 27 Sept 2021

Copyright $\odot 2020$ The Author(s). This is an Open Access article distributed under the terms of Creative Commons AttributionNonCommercial-NoDerivatives 4.0 International (CC BY-NC-ND 4.0 ), which permits anyone to share, use, reproduce and redistribute in any medium, provided the original author and source are credited.
ABSTRACT: Background: Both non- and under-utilization of antenatal services can lead to poor materno-fetal outcomes. Perception of the effectiveness, safety and timeliness of the services by pregnant women may substantially affect the utilization. Objectives: The objectives of this study were to determine pregnant women's perception of the effectiveness, safety and timeliness of the antenatal services provided by midwives, and the relationships between effectiveness, safety and timeliness of antenatal services at government-owned healthcare facilities in South-South Nigeria. Method: A cross-sectional research design was adopted for the study. Multistage sampling technique was used to select 30 primary, secondary and tertiary government-owned health facilities across the six States in South-South Nigeria from which 50 respondents were selected from each of the selected facilities. A total of 1,500 pregnant women were selected for the study. The instrument used for data collection was a self-developed Questionnaire on Pregnant Women's Perception of the Effectiveness, Safety and Timeliness of Antenatal Services Provided by Midwives. The reliability of the instrument was established through the test-retest method using Cronbach's alpha which yielded co-efficient of 0.715. Data collected were analyzed using frequencies, percentages, mean and Spearman Rank order correlation. Results: The result showed means of $4.27 \pm 0.68$, $3.72 \pm 1.03,3.23 \pm 1.17$ respectively for pregnant women's perceived effectiveness, safety and timeliness of antenatal services provided by midwives. Significant relationships also existed between safety and effectiveness (rho $=0.33, p<0.001$ ), as well as between timeliness and effectiveness (rho $=0.10, p<0.001$ ) of the antenatal services. Conclusion: Pregnant women in South-South Nigeria had a positive perception of effectiveness, safety and timeliness of the antenatal services provided by midwives. Midwives in government-owned healthcare facilities should conduct regular evaluations to get feedback from pregnant women regarding the quality of antenatal services they provide.

KEYWORDS: Effectiveness, Safety, Timeliness, Antenatal Services, Midwives, Perception, Pregnant Women 


\section{INTRODUCTION}

\section{Background of the Study}

Nigeria, with a maternal mortality ratio (MMR) of 814 per 100,000 live births compared to global average of 210 , undoubtedly needs an improvement in the quality of antenatal service delivery ${ }^{[1]}$. The third goal in Sustainable Development Goals (SDG) is "Ensure healthy lives and promote well-being for all at all ages"[2]. Precisely, target 3.1 of SDG aims at reducing the global maternal mortality ratio to less than 70 per 100000 live births by year $2030^{[3]}$. An effective package of antenatal care reduces perinatal and maternal mortality, complication rate and rate of Caesarean birth or operative intervention ${ }^{[4]}$. Antenatal care activities found to be effective were categorized into three general areas by World Health Organization ${ }^{[5]}$. The areas include screening for health and socioeconomic conditions likely to increase the possibility of specific adverse outcomes, providing therapeutic interventions known to be beneficial and educating pregnant women about planning for safe birth, emergencies during pregnancy, as well as how to deal with them.

The screening procedures which include blood pressure measurement, urine testing ${ }^{[6]}$ as well as blood testing and antibody screening ${ }^{[7]}$ amongst others are cost effective because they help in early detection and prompt treatment of abnormal findings in order to prevent complications. Therapeutic interventions such as prevention of mother-to-child transmission (PMTCT) of human immunodeficiency virus infection, administration of antibiotics for the treatment of asymptomatic bacteriuria and other infections, corticosteroids for prevention of preterm births, as well as the treatment of chronic illnesses in pregnancy are effective in the prevention of poor materno-fetal outcomes ${ }^{[5,8]}$. Other effective therapeutic interventions are administration of antimalarial prophylaxis, calcium supplementation and vitamin supplementation ${ }^{[9]}$. The education of pregnant women on emergencies in pregnancy enables them to identify such emergencies early, successfully engage in the decision making process regarding their management and cooperate with caregivers, thereby enhancing fetal and maternal health outcomes $^{[9]}$.

Antenatal care is considered as a focused strategy to reduce maternal mortality, but delivering care in an unsafe environment will thwart this strategy ${ }^{[10]}$. It is therefore important to ensure that the structural quality of available health facilities providing antenatal care is safe and good enough for patronage in order to achieve SDG target 3.1 ${ }^{[11]}$. Health service consumers are bound to make the choice of where to receive health care based on some factors ${ }^{[12]}$. Typically, such factors include cleanliness of the health facility ${ }^{[13]}$ or the infrastructural conditions like the building and equipment ${ }^{[12]}$. It is for this reason that the private health sector is sometimes preferred to the public health sector because clients will not use a product or provider that does not meet their taste unless they have no choice ${ }^{[13]}$. Meeting health care needs go beyond the services to include environmental conditions that are conducive. Poor conditions of health facilities like benches without backrest, insufficient chairs, overcrowded and stuffy space provided for waiting can provoke discomfort ${ }^{[10]}$. Also, dirty clinic environments, latrines and inadequate water supply for adequate hand washing may lead to spread of infections like nosocomial infections among others, thereby increasing cost of treatment, hospital stay and negatively impacting the health cum experience of the individual ${ }^{[13]}$.

Another major reason for high MMR and poor patient experience in Nigeria is delay in accessing maternal health care at health facilities ${ }^{[1,14]}$. In some antenatal clinics, pregnant 
women spend $6.5 \pm 2$ hours waiting to be attended to at different service points ${ }^{[15]}$. Waiting to receive care can be frustrating if it takes a long time ${ }^{[15]}$. In fact, extended waiting time will negatively impact the experience of care ${ }^{[16]}$ and can affect subsequent utilization of the facility ${ }^{[17]}$. Unfortunately, long waiting time is a major factor cited by women for dissatisfaction with the quality of care in health facilities in Nigeria and other countries ${ }^{[14]}$. Some factors identified to be responsible for delays and long waiting times in health facilities include inadequate staffing with attendant excessive workload experienced by health providers ${ }^{[18]}$. With expanding availability of newer health interventions, more patients are seeking care in outpatient facilities which is outstripping the public sector health workforce capacity of many developing countries ${ }^{[19]}$. WHO targeted 2.5 doctors, nurses and midwives per 1,000 population ${ }^{[20]}$. Going by WHO standards, Nigeria is not on track to meet this benchmark with a Nurse-Patient ratio of 1: 1,066 and Doctor-Patient ratio of 1:53,333, alongside the presently low employment rate ${ }^{[21]}$. This national emergency has contributed to health workers dissatisfaction, burnout and ultimately poor patient experience as a result of long waiting time and poor client flow.

An important aspect of care that has been highlighted to explain why women either do not access services at all, access them late or suffer an unavoidable adverse outcome despite timely presentation, relates to the concept of quality of care ${ }^{[22]}$. According to WHO, quality of care refers to the extent to which health care services provided to a client or patient improves desired health outcomes ${ }^{[23]}$. In order to achieve this, health care must among other attributes be safe, effective and timely ${ }^{[24]}$. The implication is that an understanding of maternal perception can substantially help midwives to improve their performance in the aspects of antenatal service that impacts pregnant women's perception. The perception of health service consumers is one of the most important qualitative indices of health care provision and has special relevance in antenatal care because it affects the degree to which pregnant women will utilize and comply with antenatal services for better materno-fetal outcomes ${ }^{[25]}$. It is against this background that the researchers in this study, explored the pregnant women's perception of the effectiveness, safety and timeliness of antenatal services provided by midwives.

\section{Research Questions}

1. What is pregnant women's perception of the safety of antenatal services provided by midwives at government-owned health care facilities in South-South, Nigeria?

2. To what extent do pregnant women perceive the effectiveness of antenatal procedures performed by midwives at government-owned health care facilities in South-South, Nigeria?

3. How do pregnant women perceive the timeliness in the provision of antenatal care by midwives at government-owned health care facilities in South-South, Nigeria?

\section{Research Hypotheses}

The following hypotheses were formulated to guide the study.

1. There is no significant relationship between pregnant women perception about the safety and effectiveness of antenatal services provided by midwives at government-owned health care facilities in South-South, Nigeria 
2. There is no significant relationship between pregnant women perception about the timeliness and effectiveness of antenatal services provided by midwives at governmentowned health care facilities in South-South, Nigeria

3. There is no significant relationship between pregnant women perception about the timeliness and safety of antenatal services provided by midwives at government-owned healthcare facilities in South-South, Nigeria

\section{METHOD}

\section{Study Design}

This study was a cross sectional survey.

\section{Area of the Study}

Government-owned healthcare facilities in the South-South geopolitical zone of Nigeria were used for the study. Akwa Ibom, Bayelsa, Cross River, Delta, Edo and Rivers are the six States that comprise the South-South geopolitical zone. Each State has Primary, Secondary and Tertiary levels of government-owned healthcare facilities that provide antenatal services to pregnant women.

\section{Population of the Study}

The population of the study consisted of all pregnant women attending antenatal clinic in all the government-owned Primary, Secondary and Tertiary level healthcare facilities in the six States of the South-South geo-political zone of Nigeria.

\section{Sample Size and Sampling Method}

The sample size was determined using Power Analysis Formula by Creative Research Systems $^{[26]}$. Multi-stage sampling technique was used to select the pregnant women for the study. In the first stage, simple random sampling technique was adopted in selecting one tertiary level healthcare facility from each State. This technique allowed all the tertiary healthcare facilities equal chance to be selected in States with more than one tertiary healthcare facility. Simple random sampling was used to select two secondary and two primary level healthcare facilities from each State. This technique ensured that each healthcare facility had an equal chance of being selected within the group. This gave a total of 30 healthcare facilities. In the second stage, a simple random sampling technique was used to select 50 pregnant women from each of the 30 government-owned health facilities. This technique allowed every pregnant woman in each facility to have equal opportunity of being selected for the study. The sample size of this study was 1500 pregnant women.

\section{Instrument}

Questionnaire on Pregnant Women's Perception of the Effectiveness, Safety and Timeliness of Antenatal Services Provided by Midwives (QPWPESTASPM) developed by the researchers was used for data collection in this study. QPWPESTASPM contains a total of twenty seven (27) items and comprises two (2) sections (Sections A and B). Section A elicited information 
on the Sociodemographic-obstetric characteristics of the respondents (age, parity, level of education, etc.). Section B comprised twenty (20) items which were used to elicit information on effectiveness (e.g. antenatal care received is in preparation for safe delivery, screening procedures performed during antenatal visit were to detect abnormalities, the treatments offered during antenatal visit are important, etc.), safety (e.g. the working area of the midwife is clean, the waiting area is clean, the toilets are clean, etc.), and timeliness (e.g. midwives are not in a hurry when providing care, time spent at antenatal clinic per visit is not long, waiting time is not prolonged by the lateness of the midwife, etc.). Section B of QPWPESTASPM was designed into a five-point rating scale namely: Strongly Agree $=5$ points, Agree $=4$ points, Uncertain $=3$ points, Disagree $=2$ points and Strongly Disagree $=1$ point .

Copies of the QPWPESTASPM along with the research questions and hypotheses of the study were given to three experts in Maternal and Child Health, Measurement and Evaluation, and Statistics to determine the face and content validity of the instrument. A reliability test was conducted using a test-retest method to measure the reliability of the instrument. Cronbach's Alpha yielded a Coefficient of 0.715 .

\section{Ethical Consideration}

Ethical approval for the study was obtained from the Health Research Ethics Committee of the Ministries of Health of Akwa Ibom State, Bayelsa State, Cross River State, Delta State, Edo State, and Rivers State. The researchers obtained informed consent from the health facility heads to be allowed access to the respondents. The respondents were informed that their participation in the study was voluntary and informed consent was obtained from them. The respondents were assured of anonymity, privacy and confidentiality during and after data collection.

\section{Data Collection}

Copies of the questionnaire were administered face to face by the researchers and two (2) assistants in each of the selected tertiary and secondary health facilities as well as one assistant in each Primary Healthcare Facility. Data collection was done after antenatal sessions on the antenatal clinic days of all selected facilities. The completed copies of the questionnaire were retrieved on the spot and there was $100 \%$ return rate. The data collection lasted for a period of two (2) months.

\section{Data Analysis}

Data collected from QPWPESTASPM were analyzed using frequencies, percentages, mean and standard deviation. The research questions were answered using mean. Mean score of 3 and above indicated positive perception and a mean score below 3 indicated negative perception. The hypotheses were tested using Spearman rank order correlation at 0.05 level of significance. The data analysis was done using Statistical Package for Social Sciences (SPSS) version 22. All the results were presented in tables. 


\section{RESULTS}

Table 1: Socio Demographic-Obstetric characteristics of respondents

\section{$\mathbf{S} / \mathbf{N}$ \\ 1. Variables \\ Age (in years)}

4. Occupation

5. Religion

6.

7.

\section{Variable Classification}

18-24

25-31

32-38

39-45

46 and above

None

1

2-4

5 and above

3. Level of education

Gestational age at

booking (in months)

Health care facility where antenatal care was being received
Non-formal

Primary

Secondary

Tertiary

Nil

Farming

Artisan

Business/Trading

Employed

Christianity

Islam

Traditional African Religion

3 or less

4-6

7 or more

Primary health facility

Secondary health facility

Tertiary health facility

\section{Frequency Percentage}

296

19.73

60.93

17.60

0.87

0.87

16.67

22.60

55.93

4.80

0.13

2.87

38.33

58.67

880

33.27

499

0.93

4.80

34

27

97.13

2.00

0.87

13

14.87

78.40

1176

6.73

$600 \quad 40$

$600 \quad 40$

$300 \quad 20$

Table 1 shows that the majority $914(60.93 \%)$ of the respondents were within the age bracket of 25-31years, while the minority $26(1.74 \%)$ were aged 39years and above. $839(55.93 \%)$ of the pregnant women had 2-4 previous deliveries, while $72(4.80 \%)$ had 5 and above previous deliveries. $880(58.67 \%)$ of the respondents had a tertiary level of education, while the least number $2(0.13 \%)$ had a non-formal level of education. The occupation of $510(34 \%)$ respondents was business/trading, while $14(0.93 \%)$ were farmers. $1457(97.13 \%)$ of the respondents were Christians, while a few $13(0.87 \%)$ practiced Traditional African Religion. Among the respondents, $223(14.87 \%)$ booked at gestational age of 3months or less, while 101 $(6.73 \%)$ booked at gestational age of 7 months and above. 300 (20\%) of the pregnant women received antenatal care in tertiary health facilities. 
Table 2: Perception of Pregnant Women about the Effectiveness of Antenatal Procedures Performed by Midwives 1500

\begin{tabular}{|c|c|c|c|c|c|c|c|c|}
\hline$\dot{\mathbf{S}} / \mathbf{N}$ & $\begin{array}{l}\text { Effectiveness of Antenatal } \\
\text { Procedures Performed by } \\
\text { Midwives }\end{array}$ & $\begin{array}{l}\text { SD } \\
\text { f }(\%)\end{array}$ & $\begin{array}{l}\text { D } \\
\text { f }(\%)\end{array}$ & $\begin{array}{l}\mathrm{U} \\
\mathbf{f}(\%)\end{array}$ & $\begin{array}{l}\mathbf{A} \\
\mathbf{f}(\%)\end{array}$ & $\begin{array}{l}\text { SA } \\
\text { f }(\%)\end{array}$ & Mean & $\begin{array}{l}\text { Std } \\
\text { Dev. }\end{array}$ \\
\hline & $\begin{array}{l}\text { Screening procedures performed } \\
\text { during antenatal visit prevent us from } \\
\text { developing complications }\end{array}$ & $0(0)$ & $0(0)$ & $\begin{array}{l}200 \\
(13.33)\end{array}$ & $\begin{array}{l}500 \\
(33.33)\end{array}$ & $\begin{array}{l}800 \\
(53.33)\end{array}$ & $4.40 *$ & 0.71 \\
\hline & $\begin{array}{l}\text { Complications if present are detected } \\
\text { early and promptly treated }\end{array}$ & $0(0)$ & $0(0)$ & $0(0)$ & $\begin{array}{l}700 \\
(46.67)\end{array}$ & $\begin{array}{l}800 \\
(53.33)\end{array}$ & $4.46^{*}$ & 0.50 \\
\hline & $\begin{array}{l}\text { Health status of pregnant women are } \\
\text { generally assessed during every visit } \\
\text { to the health facility }\end{array}$ & $0(0)$ & $0(0)$ & $\begin{array}{l}100 \\
(6.67)\end{array}$ & $600(40)$ & $\begin{array}{l}800 \\
(53.33)\end{array}$ & $4.40 *$ & 0.61 \\
\hline & $\begin{array}{l}\text { The midwife examines the condition } \\
\text { of the baby in the womb and informs } \\
\text { the pregnant woman }\end{array}$ & $0(0)$ & $0(0)$ & $\begin{array}{l}301 \\
(20.07)\end{array}$ & $\begin{array}{l}657 \\
(43.8)\end{array}$ & $\begin{array}{l}542 \\
(36.13)\end{array}$ & $4.10 *$ & 0.70 \\
\hline & $\begin{array}{l}\text { Every treatment due for the pregnant } \\
\text { woman (e.g routine drugs, pelvic } \\
\text { examination, e.t.c.) are given to } \\
\text { pregnant women during every visit }\end{array}$ & $0(0)$ & $0(0)$ & $0(0)$ & $\begin{array}{l}760 \\
(50.67)\end{array}$ & $\begin{array}{l}740 \\
(49.33)\end{array}$ & $4.43 *$ & 0.50 \\
\hline & $\begin{array}{l}\text { All routine examinations (e.g urine } \\
\text { testing, BP check, e.t.c.) are provided }\end{array}$ & $0(0)$ & $0(0)$ & $0(0)$ & $\begin{array}{l}640 \\
(42.67)\end{array}$ & $\begin{array}{l}860 \\
(57.33)\end{array}$ & $4.50 *$ & 0.50 \\
\hline & $\begin{array}{l}\text { Would have benefitted more from } \\
\text { antenatal care if booking was earlier }\end{array}$ & $0(0)$ & $\begin{array}{l}400 \\
(26.67)\end{array}$ & $\begin{array}{l}200 \\
(13.33)\end{array}$ & $420(28)$ & $480(32)$ & $3.58 *$ & 1.26 \\
\hline & $\begin{array}{l}\text { Overall Mean } \\
\text { ositive perception }\end{array}$ & & & & & & 4.27 & 0.68 \\
\hline
\end{tabular}

Table 2 shows that mean for screening procedures performed during antenatal visit prevented complications $=4.40$, early detection of complications and prompt treatment $=4.46$, mean for assessment of health status of pregnant women during every visit to the health facility $=4.40$, examination of the condition of the baby in the womb by the midwife and informs the pregnant woman $=4.10$, every treatment due for the pregnant woman (e.g routine drugs, pelvic examination, e.t.c.) was given to pregnant women during every visit $=4.43$, all routine examinations (e.g urine testing, BP check, e.t.c.) were provided $=4.50$ and would have benefitted more from antenatal care if booking was earlier $=3.58$. Average mean score $=4.27$ indicating that pregnant women had positive perception about the effectiveness of antenatal procedures performed by midwives. 
Table 3: Perception of Pregnant Women about the Safety of Antenatal Services Provided by Midwives

$$
n=1500
$$

\begin{tabular}{|c|c|c|c|c|c|c|c|c|}
\hline$\dot{\mathbf{S}} / \mathbf{N}$ & $\begin{array}{l}\text { The Safety of Antenatal } \\
\text { Services Provided by } \\
\text { Midwives }\end{array}$ & $\begin{array}{l}\text { SD } \\
\text { f }(\%)\end{array}$ & $\begin{array}{l}\text { D } \\
\mathbf{f}(\%)\end{array}$ & $\begin{array}{l}\mathrm{U} \\
\mathbf{f}(\%)\end{array}$ & $\begin{array}{l}\text { A } \\
f(\%)\end{array}$ & $\begin{array}{l}\text { SA } \\
\text { f }(\%)\end{array}$ & Mean & $\begin{array}{l}\text { Std } \\
\text { Dev. }\end{array}$ \\
\hline & $\begin{array}{l}\text { The environment of the } \\
\text { antenatal clinic is clean }\end{array}$ & $0(0)$ & $0(0)$ & $0(0)$ & $840(56)$ & $660(44)$ & $4.43 *$ & 0.50 \\
\hline & $\begin{array}{l}\text { Section/hall of the } \\
\text { antenatal clinic is not } \\
\text { overcrowded }\end{array}$ & $0(0)$ & $0(0)$ & $0(0)$ & $600(40)$ & $900(60)$ & $4.60 *$ & 0.49 \\
\hline & $\begin{array}{l}\text { The antenatal clinic toilets } \\
\text { are functional and clean }\end{array}$ & $\begin{array}{l}680 \\
(45.34)\end{array}$ & $0(0)$ & $\begin{array}{l}200 \\
(13.33)\end{array}$ & $420(28)$ & $200(13.33)$ & 2.64 & 1.58 \\
\hline & $\begin{array}{l}\text { Antenatal clinic has good } \\
\text { water supply }\end{array}$ & $\begin{array}{l}200 \\
(13.33)\end{array}$ & $420(28)$ & $\begin{array}{l}200 \\
(13.33)\end{array}$ & $\begin{array}{l}200 \\
(13.33)\end{array}$ & $480(32)$ & $3.23 *$ & 1.48 \\
\hline & $\begin{array}{l}\text { Midwives wash their } \\
\text { hands before touching a } \\
\text { pregnant woman }\end{array}$ & $\begin{array}{l}700 \\
(46.67)\end{array}$ & $\begin{array}{l}200 \\
(13.33)\end{array}$ & $\begin{array}{l}200 \\
(13.33)\end{array}$ & $\begin{array}{l}200 \\
(13.33)\end{array}$ & $200(13.33)$ & 2.33 & 1.49 \\
\hline & $\begin{array}{l}\text { Antenatal clinic is airy } \\
\text { enough }\end{array}$ & $0(0)$ & $0(0)$ & $0(0)$ & $\begin{array}{l}700 \\
(46.67)\end{array}$ & $800(53.33)$ & $4.53 *$ & 0.50 \\
\hline & $\begin{array}{l}\text { The examination room has } \\
\text { good light }\end{array}$ & $0(0)$ & $420(28)$ & $0(0)$ & $420(28)$ & $660(44)$ & $3.88 *$ & 1.24 \\
\hline & $\begin{array}{l}\text { Seats in the antenatal } \\
\text { clinic are sufficient }\end{array}$ & $0(0)$ & $0(0)$ & $0(0)$ & $600(40)$ & $900(60)$ & $4.60 *$ & 0.49 \\
\hline & $\begin{array}{l}\text { Seats in the antenatal } \\
\text { clinic have backrests }\end{array}$ & $240(16)$ & $420(28)$ & $0(0)$ & $420(28)$ & $420(28)$ & $3.24 *$ & 1.50 \\
\hline & Overall Mean & & & & & & 3.72 & 1.03 \\
\hline
\end{tabular}

\section{*Positive perception}

Table 3 shows that the environment of the antenatal clinic was clean with mean $=4.43$, section/hall of the antenatal clinic was not overcrowded with mean $=4.60$, antenatal clinic had good water supply with mean $=3.23$, antenatal clinic was airy enough with mean $=4.53$, the examination room had good light with mean $=3.88$, seats in the antenatal clinic were sufficient with mean $=4.60$ and seats in the antenatal clinic had backrests with mean $=3.24$. Overall average mean score was 3.72 indicating that pregnant women had positive perception about the safety of antenatal services provided by midwives. 
Table 4: Perception of Pregnant Women about Timeliness in the Provision of Antenatal Services by Midwives $n=1500$

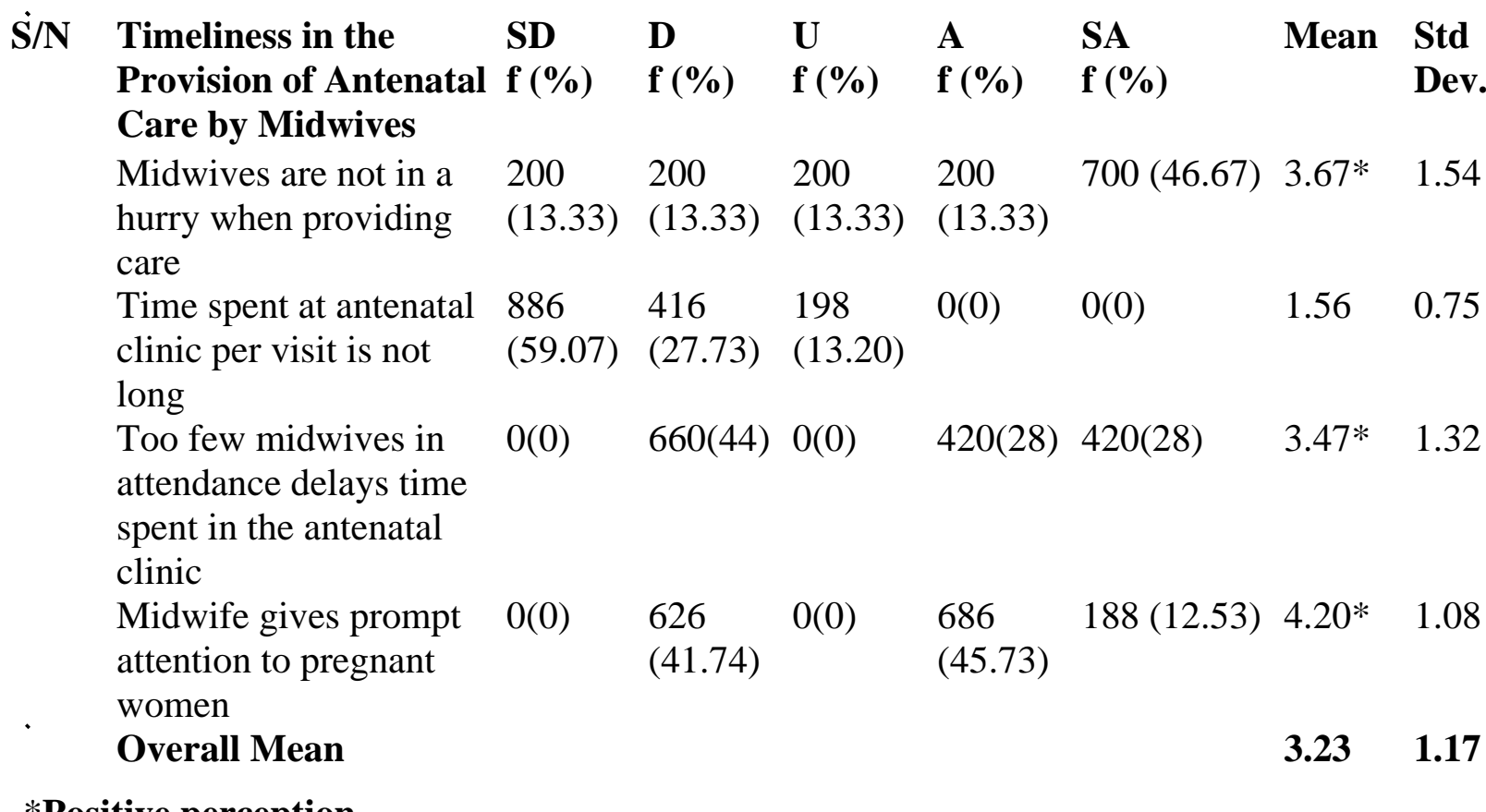

*Positive perception

Table 4 shows that mean for midwives not in a hurry when providing care $=3.67$, too few midwives in attendance delayed time spent in the antenatal clinic $=3.47$ and midwives gave prompt attention to pregnant women $=4.20$. The overall average mean score was 3.23 indicating that pregnant women had positive perception about timeliness in the provision of antenatal care by midwives.

Table 5: Spearman Rank order Correlation showing Relationships between Perceived Effectiveness, Safety and Timeliness of Antenatal Services Provided by Midwives

\begin{tabular}{cllc}
\hline Hypothesis & Variables & rho & P \\
\hline 1. & $\begin{array}{l}\text { Perception about safety and effectiveness of antenatal } \\
\text { services }\end{array}$ & 0.33 & $<0.001^{*}$ \\
2. & $\begin{array}{l}\text { Perception about timeliness and effectiveness of antenatal } \\
\text { services }\end{array}$ & 0.10 & $<0.001^{*}$ \\
3. & Perception about timeliness and safety of antenatal services & 0.01 & 0.83 \\
\hline
\end{tabular}

$*=$ Significant at $\mathbf{p}<0.05$ 
Hypothesis 1: There is no significant relationship between the perception of pregnant women about the safety and effectiveness of antenatal services provided by midwives at government-owned health care facilities in South-South, Nigeria

Table 5 shows that rho $=0.33$ and $p$-value $<0.001$. The null hypothesis was rejected. There was a significant relationship between the perception of pregnant women about the safety and effectiveness of antenatal services provided by midwives at government-owned healthcare facilities in South-South, Nigeria.

Hypothesis 2: There is no significant relationship between the perception of pregnant women about the timeliness and effectiveness of antenatal services provided by midwives at government-owned health care facilities in South-South, Nigeria

Table 5 shows that rho $=0.10$ and p-value $<0.001$. The null hypothesis was rejected. Significant relationship existed between the perception of pregnant women about the timeliness and effectiveness of antenatal services provided by midwives at government-owned healthcare facilities in South-South, Nigeria.

Hypothesis 3: There is no significant relationship between the perception of pregnant women about the timeliness and safety of antenatal services provided by midwives at government-owned health care facilities in South-South, Nigeria

Table 5 shows that rho $=0.01$ and $p$-value $=0.83$. The null hypothesis was accepted. Significant relationship did not exist between the perception of pregnant women about the timeliness and safety of antenatal services provided by midwives at government-owned health care facilities in South-South, Nigeria.

\section{DISCUSSION}

Perception of pregnant women about the effectiveness of antenatal procedures performed by midwives

The overall mean score for the effectiveness of antenatal procedures performed by midwives was 4.27 (Table 2) indicating that pregnant women had positive perception. In the opinion of the pregnant women, routine antenatal examinations including fetal and general health assessment were performed, adequate treatment was given and booking earlier would have been more beneficial. This finding is in line with the observation of researchers ${ }^{[27]}$ who found that the majority of pregnant women in South India were satisfied with the tests done, examinations performed and enquiries made by midwives. It has been noted that measurement of blood pressure, urine test, blood test and iron supplementation were the antenatal screening and medication services most commonly offered to pregnant women, and that pregnant women who booked early expressed more positive perception about the routine antenatal examinations provided by midwives in South-West Nigeria ${ }^{[1]}$. Also reports have shown that iron and folic acid tablets were the routine drugs most frequently prescribed for pregnant women, while blood pressure check, auscultation of fetal heart sound and abdominal palpation were examinations that were frequently performed to assess the maternal and fetal health in pregnant women in Punjab Province ${ }^{[28]}$. Routine antenatal examinations are highly effective in the assessment of 
materno-fetal risks and early detection of complications, thereby preventing perinatal and maternal mortality ${ }^{[4]}$.

\section{Perception of pregnant women about the safety of antenatal services provided by midwives}

Overall average mean score of 3.72 (Table 3) revealed that pregnant women had positive perception about the safety of antenatal services provided by midwives. In the opinion of the pregnant women, the antenatal clinic had sufficient chairs with backrest, good ventilation, appeared clean, had good light and good source of water supply. Studies have shown that clients express satisfaction with the cleanliness of antenatal amenities in $\mathrm{Nepal}^{[29]}$. A study conducted in Accra identified that the antenatal environment and washroom were clean ${ }^{[30]}$. A clean environment prevents the spread of nosocomial infections among pregnant women and facilitates the patronage of facilities where safe antenatal care is provided ${ }^{[13]}$. Reports have shown that the majority of respondents in the government Health centres in Buea Health District in Cameroon expressed satisfaction with the cleanliness of antenatal amenities and the comfort of sitting areas ${ }^{[31]}$. Airy clinic environment enhanced comfort and attention of pregnant women during mother craft classes, thereby positively impacting the health of pregnant women in Jimma Town ${ }^{[10]}$. Also, having a good source of light when performing screening procedures is an infrastructural requirement that is highly beneficial ${ }^{[12]}$ because it enhances accurate assessment and detection of abnormalities for prompt intervention to be initiated ${ }^{[32]}$. However, it was found out that the antenatal clinic at the University College Hospital, Ibadan had inadequate water supply and unsatisfactory toilet and bathroom facilities which contradicted the findings of this study ${ }^{[33]}$. Having adequate water supply in antenatal clinics is ideal because it facilitates adequate hand washing and cleanliness of the clinic environment including the toilet facilities ${ }^{[13]}$.

\section{Perception of pregnant women about timeliness in the provision of antenatal services by midwives}

The overall mean score of 3.23 (Table 4) indicated that pregnant women had positive perception about timeliness in the provision of antenatal care. According to them, antenatal care was rendered promptly and unhurriedly. Studies have shown that pregnant women were satisfied with the time spent on waiting in the antenatal clinic in South India ${ }^{[27]}$. Contrarily, reports have shown that pregnant women spent long hours waiting to receive care at antenatal clinics in Southern Ethiopia ${ }^{[34]}$. This could suggest that midwives provided detailed and unhurried care but because of inadequate staffing, many pregnant women experienced long waiting times. Common factors responsible for delays and long waiting time in health facilities include inadequate staffing with attendant excessive workload experienced by health providers $^{[18]}$.

\section{Relationship between pregnant women perception about the safety and effectiveness of antenatal services}

The p-value $<0.001$ (Table 5) showed that there was a significant relationship between pregnant women's perception about the safety and effectiveness of antenatal services provided by midwives at government-owned health care facilities in South-South Nigeria. Health service consumers make the choice of where to receive health care after considering several factors including the infrastructural condition of the facility which encompasses the building and 
equipment ${ }^{[12]}$. An effective ANC package which provides pregnant women with a broad range of safe services, reduces perinatal and maternal mortality ${ }^{[4]}$. Absence of an effective health programme was identified as a variable influencing late initiation of $\mathrm{ANC}^{[35]}$. It is also noteworthy that previous positive pregnancy outcomes for which women did not access care made them less motivated to initiate antenatal care early ${ }^{[35]}$.

\section{Relationship between pregnant women's Perception about the timeliness and effectiveness of antenatal services}

The p-value $<0.001$ (Table 5) showed that a significant relationship existed between the perception of pregnant women about the timeliness and effectiveness of antenatal services provided by midwives at government-owned health care facilities in South-South Nigeria. In the researcher's opinion, timely and effective care are evidence of responsive care, and providing responsive antenatal care is key to ensuring that pregnant women return for their follow-up appointments; compliance with subsequent visits will lead to healthy pregnancy outcomes. Extended waiting time will negatively impact the experience of care ${ }^{[16]}$.

\section{Relationship between pregnant women perception about the timeliness and safety of antenatal services}

The p-value of 0.83 (Table 5) showed that a significant relationship did not exist between the perception of pregnant women about the timeliness and safety of antenatal services provided by midwives at government-owned health care facilities in South-South Nigeria. Two of the reasons for a high maternal mortality rate in Nigeria are low utilization and delay in accessing care at health facilities for maternal health care ${ }^{[14]}$. In the researcher's opinion, receiving antenatal care in an unsafe environment will negatively impact the health of users and may ultimately contribute to delay in accessing care and low utilization. A person will not use a product or provider that does not meet his/her taste unless he/she has no choice ${ }^{[13]}$.

\section{CONCLUSION}

Pregnant women in South-South Nigeria generally had a positive perception of the effectiveness, safety and timeliness of antenatal services provided by midwives. However, they displayed negative perceptions in few specific items of the antenatal services provided by midwives. This is a challenge to midwives to improve their skills in the antenatal services they render to pregnant women. In addition, significant relationships existed between safety and effectiveness, as well as between timeliness and effectiveness. These aspects impact the perception of antenatal care quality, and focusing on them will generally improve the outcome of antenatal care. 


\section{REFERENCES}

[1] Fagbamigbe A, Idemudia E. (2015). Assessment of quality of antenatal care services in Nigeria: Evidence from a population-based survey. Reproductive Health Journal, 12(1), 78-88.

[2] United Nations Development Programme. (2019). Sustainable development goals. Retrieved September 30, 2019, from https://undp.org/content/undp/en/home/sustainable-development-goals.html

[3] United Nations. (2018). 17 sustainable development goals. Retrieved November 10, 2018, from http://un.org/sustainabledevelopment/\&sa=U\&ved=2ahUKEwid3.../

[4] Olawale G. (2018). ANC curbs high infant, maternal mortality. Retrieved August 25, 2018, from https://www.vanguardngr.com/2018/03/anc-curbs-high-infant-maternalmortality/

[5] World Health Organization. (2016). WHO recommendations on antenatal care for a positive pregnancy experience. Geneva: World Health Organization.

[6] Petrenko N. (2016). Hypertensive disorders in pregnancy. Retrieved February 2, 2018, from http://intranet.tdmu.edu.ua/data/kafedra/internal/ginecology2/classes_stud/en/nurse/bsn/ $\mathrm{p}$

tn/2/Elective\%20course $\% 200 B G / 04 . \% 20$ Hypertensive\%20disorders\%20in\%20pregnan cy.htm

[7] Shriver E. (2017). What are some common complications of pregnancy? Retrieved February 27, 2018, from

www.nichd.nih.gov/health/topics/pregnancy/conditioninfo/pages/complica tions.aspx\#highblood

[8] Burd I, Finke A. (2017). Common tests during pregnancy. Retrieved September 13, 2018, from www.urmcrochester.edu/encyclopedia/content.aspx ?contenttypeid $=85$ contentid $=\mathrm{P}$ 01241

[9] Christopher P, Lianne S, Erin V, Arantza M, Robert P. (2011). Social and cultural factors affecting uptake of interventions for malaria in pregnancy in Africa: A systematic review of the qualitative research. Retrieved from http://journals.plos.org/plosone/ article?id=10.1371/journal.pone.0022452

[10] Chemir F, Alemseged F, Workneh D. (2014). Satisfaction with focused antenatal care service and associated factors among pregnant women attending focused antenatal care at health centres in Jimma town, Jimma zone, South West Ethiopia; a facility based cross-sectional study triangulated with qualitative study. Biomed Central Research Notes, 7(1), 164-172

[11] Mundodan J. (2015). Structural quality of antenatal clinics in the public health sector in a Northern district in Kerala, India. International Journal of Community Medicine and Public Health, 2(4), 513-519

[12] Uchendu O, Ilesanmi O, Olumide A. (2013). Factors influencing the choice of health care providing facility among workers in a Local Government Secretariat in South Western Nigeria. Annals of Ibadan postgraduate medicine, 11(2), 87-95.

[13] Abodunrin O, Bamidele J, Olugbenga-Bello A, Parakoyi D. (2010). Preferred choice of health facilities for healthcare among adult residents in Ilorin Metropolis, Kwara State, Nigeria. International Journal of Health Research, 3(2), 79-86. 
[14] Okonofua F, Ogu R, Agholor K, Okike O, Abdus-salam R, Gana M, Randawa A, Abe E, Durodola A, Galadanci H, The WHARC WHO FMOH MNCH Implementation Research Study Team. (2017). Qualitative assessment of women's satisfaction with maternal health care in referral hospitals in Nigeria. Retrieved from http://creativecommons.org/licenses/by/4.0/ on 2/2/2018

[15] Donkor E, Obed S. (2012). Waiting time and women's satisfaction at an antenatal clinic in Ghana. African Journal of Midwifery and Women's Health, 6(1), 68-74

[16] McGowan H, Gopeesingh K, O’Kelly P, Gillligan P. (2018). Emergency department overcrowding and the full capacity protocol cross over study: What patients who have experienced both think about being an extra patient in the emergency department or a ward. Irish Medical Journal 111(7), 788

[17] Umar I, Oche M, Umar A. (2011). Patient waiting time in a tertiary health institution in Northern Nigeria. Journal of Public Health and Epidemiology, 3(2), 78-82.

[18] Akinyinka M, Adebayo B, Wright K, Adeniran A. (2016). Client waiting time in an urban primary health care centre in Lagos. Journal of Community Medicine and Primary Health Care, 28(1), 17-24.

[19] Wagenaar B, Gimbel S, Hoek R, Pfeiffer J, Michel C, Cuembelo F, Quembo T, Afonso P, Gloyd S, Lambdin B, Micek M, Porthe V, Sherr K. (2016). Wait and consult times for primary healthcare services in central Mozambique: A time-motion study. Global Health Action, 30(1), 74-81.

[20] Barrientos M. (2015). Health indicators. Retrieved March 13, 2019, from www.indexmundi. com/facts/indicators/SH.MED.NUMW.P3

[21] Vanguard Nigeria. (2015). Shortage of medical personnel: Tougher times ahead for Nigerians (1). Retrieved January 1, 2019, from https://www.vanguardngr.com/2015/01/shortage-medical-personnel-tougher-timesahead-nigerians-1/

[22] Hulton L, Matthews Z, Stones W. (2008) A framework for the evaluation of quality of care in maternity services. Retrieved February 1, 2018, from www.mamaye.org/sites /default/files/u436/Hulton_2000_Framework\%20for \%20maternity\%20QoC.pdf

[23] World Health Organization. (2017a). Quality of care. Retrieved September 23, 2018, from www.who.int/maternal_child_adolescent/topics/quality-of-care/definit ion/en/

[24] World Health Organization. (2018a). Maternal, newborn, child and adolescent health. Retrieved October 22, 2018, from www.who.int/maternal_child_adolescent/topics/definition/en/

[25] Mohammed A, Amal A. (2015). Health Education during Antenatal Care: The Need for More. International Journal of Women's Health, 7(1), 239-242.

[26] Creative Research Systems. (2016). Sample size formulas for our sample size calculator. Retrieved April 3, 2019, from www.surveysystem.com/sample-sizeformula.htm

[27] Ruby P, David K, Siva R, Vimala T, Rahman S, Sankarapandian V. (2016). Satisfaction of antenatal mothers with the care provided by nurse-midwives in an urban secondary care unit. Journal of Family Medicine and Primary Care, 5(2), 420-423.

[28] Majrooh M. Hasnain S, Akram J, Siddiqui A, Memon Z. (2014). Coverage and quality of antenatal care provided at primary health care facilities in the 'Punjab' Province of Pakistan. Retrieved February 22, 2018, from http://journals.plos.org/plosone/article? $\mathrm{id}=10.1371 /$ journal.pone. 0113390 
[29] Paudel Y, Mehata S, Paudel D, Dariang M, Aryal K, Poudel P, King S, \& Barnett S. (2015). Women's satisfaction of maternity care in Nepal and its correlation with intended future utilization. International Journal of Reproductive Medicine, 2015(1), 78-87.

[30] Freeman F. (2015). Assessment of clients' satisfaction with quality of antenatal care at Korle-Bu Teaching Hospital. A Dissertation submitted to the School of Public Health, University of Ghana, Legon.

[31] Edie G, Obinchemti T, Tamufor E, Njie M, Njamen T, Achidi E. (2015). Perceptions of antenatal care services by pregnant women attending government health centres in the Buea Health District, Cameroon, Pan African Medical Journal, 21(45), 48-58.

[32] Masi S, Bucagu M, Tuncalp O, Pena-Rosas J, Lawrie T, Oladapo O, Gulmezoglu M. (2017). Integrated Person-Centred Health Care for All Women During Pregnancy: Implementing World Health Organization Recommendations on Antenatal Care for a Positive Pregnancy Experience. Global Health: Science and Practice, 5(2), 197-201.

[33] Nwaeze I, Enabor O, Oluwasola T, Aimakhu C. (2013). Perception and satisfaction with quality of antenatal care services among pregnant women at the University College Hospital, Ibadan, Nigeria. Annals of Ibadan Postgraduate Medicine, 11(1), 22-28.

[34] Tesfaye T, Mekonnen H, Negesa L. (2017). Maternal antenatal care service satisfaction and factors associated with rural health centres, Bursa District, Sidama Zone, Southern Ethiopia: A Cross-sectional Study. Journal of Women's Health Care, 6(363), 4-20.

[35] Warri D, George A. (2020). Perceptions of pregnant women of reasons for late initiation of antenatal care: A qualitative interview study. BioMed Central Pregnancy Childbirth, 20(1), 1-12. 